\title{
Research on the Application of Online-to-offline Mode in Agricultural Products E-Commerce Based on New Retail
}

\author{
Yan Wang \\ School of Accounting and Finance, Xi'an Peihua University, Xi'an, Shaan'xi, China
}

Key words: Online-to-offline (O2O), Agricultural Products, E-commerce, New Retail.

\begin{abstract}
With the new normal state of Chinese economy, rural economy has been paid more and more attention. E-commerce of agricultural products is considered as an effective means to solve rural economic problems. At the moment of the rapid development of new retail, the e-commerce modes of agricultural products are constantly showing new changes. Firstly, based on the overview of agricultural products e-commerce and $\mathrm{O} 2 \mathrm{O}$ mode, this paper describes the application status and problem of the $\mathrm{O} 2 \mathrm{O}$ mode in agricultural products, and puts forward corresponding suggestions for the development of $\mathrm{O} 2 \mathrm{O}$ mode of agricultural products e-commerce.
\end{abstract}

\section{Introduction}

With the continuous development of new retail formats, agricultural products have greatly expanded their sales channels with the $\mathrm{O} 2 \mathrm{O}$ e-commerce mode. To a certain extent, the problem of slow sales of agricultural products has been effectively solved. Owing to its characteristics of "online consumption, offline experience", the mode of $\mathrm{O} 2 \mathrm{O}$ has been recognized by many consumers. The $\mathrm{O} 2 \mathrm{O}$ mode of agricultural products e-commerce is conducive to improving farmers' income and the competitiveness of agricultural products industry.

\section{Overview of Agricultural Products E-Commerce and O2O mode}

Agricultural products e-commerce is to use modern information technology such as the internet to provide a network trading platform for both producers and operators of agricultural products. On this platform, agricultural products exchanges, sales, payment and a series of activities are carried out. Agricultural products e-commerce can effectively take advantage of the platform advantages, so that users can directly select fruits, vegetables and other agricultural products on the platform, and the corresponding merchants can deliver directly to the door, online can complete the entire sales process.

The $\mathrm{O} 2 \mathrm{O}$ mode is to use online marketing and purchasing to drive off-line business and consumption, and to facilitate off-line transactions on the basis of the Internet. The application of the $\mathrm{O} 2 \mathrm{O}$ mode in the field of agricultural products will help to promote the transformation and upgrading of agricultural products management mode in an all-round way. Businesses can attract customers online, and consumers can screen goods and settle accounts online. Businessmen provide offline services, and the combination of online and offline mode makes the sale of agricultural products more large-scale ${ }^{[1]}$.

\section{Application Advantages of O2O Mode}

\subsection{Achieve Precision Marketing}

Through online payment, customers who drain online to offline are back online, providing controlled records for businesses and forming sales data of agricultural products. This becomes the value that the $\mathrm{O} 2 \mathrm{O}$ mode can excavate. Through the statistics and analysis of transaction data, the marketing effect can be quantified to provide more accurate marketing solutions for businesses, and consumers can also get more personalized services from them ${ }^{[2]}$. 


\subsection{Reducing Logistics Cost}

Nowadays, the important reason that restricts the development of agricultural products e-commerce has changed from Internet technology to logistics technology. Because of the high cost of logistics and the low efficiency of logistics, the consumption experience is reduced. This has become a bottleneck in the development of e-commerce for agricultural products. The emergence of the $\mathrm{O} 2 \mathrm{O}$ mode makes full use of the inventory and geographical location advantages of offline physical stores. To a certain extent, it provides a very good solution to the "last kilometer" problem, and greatly reduces logistics costs.

\subsection{Improve the Consumer Experience}

Using the offline experience store to drive the sale of agricultural products on the line, the offline retail store provides agricultural products experience, self-raising services, and cultivates customer spending habits. This will not only greatly satisfy the consumer's individual needs, but also enhance the consumer's experience. Through the rapid information dissemination of e-commerce platforms, businesses can instantly gather powerful spending power.

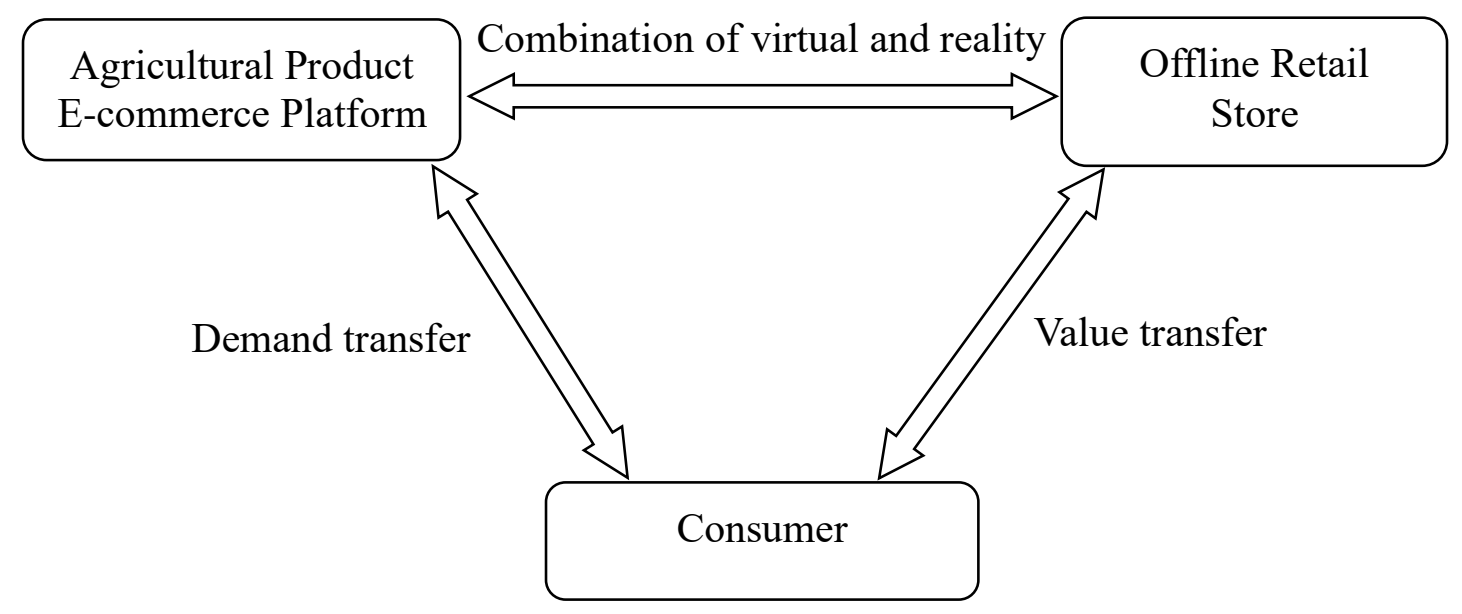

Fig.1 O2O Mode of Agricultural Products

\section{Application Status and Problems of O2O Mode in Agricultural Products}

In recent years, under the development trend of "Internet + agriculture", online sales of agricultural products have become more and more popular, and become a new economic growth point in the retail industry. In recent years, online sales of agricultural products show a trend of rapid growth. By 2016, The agricultural products e-commerce market has exceeded 170 billion yuan in China. In 2017, Chinese rural online retail sales exceeded 1.2 trillion yuan, of which $20 \%$ were agricultural products and expected to reach 250 billion yuan. In 2018, Chinese characteristic agricultural products developed rapidly, with online sales of agricultural products reaching 300 billion yuan. The Ministry of Agriculture estimates that Chinese online sales of agricultural products will reach 800 billion yuan by 2020 .

At present, the e-commerce modes mainly include $\mathrm{B} 2 \mathrm{~B}, \mathrm{~B} 2 \mathrm{C}$ and $\mathrm{C} 2 \mathrm{C}$. The main mode of agricultural products e-commerce is to trade agricultural products through Taobao, Tianmao, Jingdong and other platforms, the other is a vertical e-commerce platform specializing in selling agricultural products, such as Huinong, New Rural Business Network, etc.

With the development of Internet economy, the traditional e-commerce mode of agricultural products has been unable to meet the personalized needs of modern consumers. With the combination of online sales of agricultural products and offline physical stores, the mode of $\mathrm{O} 2 \mathrm{O}$ emerged as the times require. The $\mathrm{O} 2 \mathrm{O}$ mode of agricultural products makes full use of the advantages of online platform, local convenient logistics and offline retail stores, so that consumers can enjoy preferential prices while experiencing the quality of agricultural products offline, and 
realize instant consumption. As a new mode, users can choose their favorite products online, place orders, pay, and experience intimate services offline. In a real sense, the formation of a community-based sales mode is conducive to improving customer loyalty and promoting better sales ${ }^{[4]}$.

Although $\mathrm{O} 2 \mathrm{O}$ mode has many advantages in the new retail environment, there are still some problems. For example, the agricultural product category does not match the actual needs of consumers. Businesses take the low-cost route, which hinders their long-term development. The quality of agricultural products cannot be guaranteed. The publicity and service were not up to standard, and no users were obtained.

\section{Suggestions on Developing O2O Mode for Agricultural Products E-Commerce}

\subsection{Guiding Consumers' Online Purchase Behavior}

With the popularity of the Internet, people buy agricultural products in a variety of channels. Most consumers are used to buying in agricultural markets or supermarkets, and there are no fixed online consumption habits. According to the investigation, the homogeneity of agricultural products in the field of e-commerce is relatively high, and the characteristics of agricultural products are not obvious. Through the mode of $\mathrm{O} 2 \mathrm{O}$, we can experience agricultural products, promote sales, improve consumers' repurchase rate, and gradually guide consumers to purchase agricultural products online. Farmers can produce agricultural products customized according to the needs of consumers, focusing on the production of agricultural products with high demand frequency and characteristics.

\subsection{Standardized Operation of Agricultural Products}

Agricultural products have a greater impact on the geographical environment. The planting and picking of high-quality agricultural products should be strictly controlled at all stages. The quality, classification and grade of agricultural products should be standardized. Normalized packaging of agricultural products will also arouse consumers' interest in buying. The labeling of agricultural products and the description of basic information on the packaging of agricultural products are also the embodiment of standardization.

In addition, in order to ensure the freshness of agricultural products and prevent agricultural products from being damaged during transportation, packaging materials and fillers should be strictly screened and transported after comprehensive inspection. Agricultural products logistics mostly uses cold chain transportation, so it is necessary to improve cold chain technology ${ }^{[5]}$. In a word, standardized operation is very important for the development of e-commerce of agricultural products.

\subsection{Pay Attention to Offline Service and Online Evaluation}

When consumers buy agricultural products online, they often refer to the description and evaluation of agricultural products. User's evaluation reflects the service level of the merchants and the quality of agricultural products. It is necessary to respond to the consumer's evaluation in a timely manner, feed back the medium and poor evaluation in a timely manner, reduce the rate of poor evaluation, and enhance the trust of users. Online evaluation reflects the user's experience. Businessmen need to improve service level, attach importance to offline experience, and improve customer's purchase rate by increasing positive comments ${ }^{[6]}$.

\section{Acknowledgment}

In this paper, the research was sponsored by the Social Science Foundation Project of Shaanxi Province in 2018: Research on the Innovation mode Rural Electronic Commerce Precise Poverty Alleviation in Shaanxi (Project No. 2018D19). 


\section{Reference}

[1] Wang Ji. Basic Framework Construction and Operating Mechanism of Agricultural Product mode [J]. Commercial Economic Research, 2017 (08): 150-151.

[2] Ding Shian. Rural E-commerce Marketing and Entrepreneurship Book [M]. China Joint Press of Industry and Commerce, 2017:54-57.

[3] Liao Binbin. Theoretical and Empirical Research on the Development of Agricultural products e-commerce under the New Normal State [M]. China Social Science Press, 2016:94-96.

[4] Wang Sheng. Agricultural Products E-commerce Industry Development Research Report (2016) of Chongqing [M]. China Social Science Press, 2018:48-49.

[5] Yu Yang. Analysis of Brand Effect of Fresh E-commerce in China [J]. Commercial Economic Research, 2018:46-49.

[6] Zhang Hao, Cui Yan, Yu Lei. Comparisons of O2O Modes of Fresh Agricultural Products E-commerce [J]. Jiangsu Agricultural Science, 2018, 46 (17): 307-315. 